\title{
Perioperative Arrhythmias
}

\author{
Ali Altınbaş ${ }^{1}$, Nilay Taş ${ }^{2}$, Osman Bektaş ${ }^{3}$ \\ ${ }^{1}$ Ordu University Training and Research Hospital, Department of Anesthesiology and Reanimation, Ordu, Turkey \\ ${ }^{2}$ Ordu University School of Medicine, Department of Anesthesiology and Reanimation, Ordu, Turkey \\ ${ }^{3}$ Ordu University School of Medicine, Department of Cardiology, Ordu, Turkey
}

Received: 15 November 2017 Accepted: 06 December 2017, Published online: 28 December 2017

(C) Ordu University Institute of Health Sciences, Turkey, 2017

\begin{abstract}
Arrhythmias are the most commonly encountered cardiovascular complications during anesthesia administration. Perioperative arrhythmias disrupt the hemodynamic state of the patients and are known to cause increases in mortality and morbidity. Anesthetic agents and methods affect cardiac conduction and cause arrhythmia. At the same time, patients with additional cardiac diseases and other systemic diseases affecting the cardiovascular system have increased risk of perioperative arrhythmia. For the patient, regardless of whether due to the surgical procedure or anesthesia type, the most important effect of intraoperative arrhythmias is undoubtedly the resulting hemodynamic instability. It is possible to encounter a broad range of serious rhythm and hemodynamic disorders from rare ventricular extrasystole to malignant character arrhythmia and sudden cardiac arrest. Temperature changes occurring in the intraoperative period, hypoxia, acid-base disorders and variations in electrolyte balance are significant factors affecting the occurrence of arrhythmia. As there are many factors and mechanisms in the etiology, identifying arrhythmia under anesthesia and performing the necessary intervention in the shortest time possible has vital importance. This review deals with the importance of arrhythmia occurring in the perioperative period and methods of approach for arrhythmia.
\end{abstract}

Key words: Arrhythmias, perioperative period, anesthesia

\section{Address for correspondence/reprints:}

Ali Altınbaş

Telephone number: +90 (452) 2252344

E-mail: ali.altinbas@hotmail.com

DOI: $10.19127 / \mathrm{mbsjohs.353187}$

\section{Introduction}

Arrhythmias are cardiovascular complications commonly encountered in the perioperative period that may be very serious. The rate of arrhythmia encountered with general anesthesia administration is known to reach up to $70 \%$ (Erdemli and Çekmen, 2010; Yapıcı and Azizoğlu, 2015; Kwon and Kim, 2017). During the patient's hospital stay beginning in the period before surgery, anesthesia and reanimation clinicians encounter arrhythmias and have to intervene. Perioperative arrhythmias are known to lengthen hospital stays and increase mortality and morbidity (Polanczyk et al., 1998; Thompson and Balser, 2004). The patients' clinical properties, surgical procedure and anesthesia method play an important role in the occurrence of perioperative arrhythmias. During physical examination, patients without any rhythm disorder identified may have diseases or syndromes that 
cause arrhythmias (Timuralp, 2010). Arrhythmias that are usually identified during preoperative assessment and can be controlled by appropriate methods may be encountered many times unexpectedly during the intraoperative and postoperative period. Generally, these arrhythmias, occurring linked to an underlying disease, occur independently of the predisposing factors of surgical cases (Tyler, 2015). The localization and dimension of the surgical procedure may facilitate the occurrence of arrhythmias. For example, strabismus surgery is a risk factor for bradycardia, while cardiac surgeries may precipitate different arrhythmias (Kwon and Kim, 2017). Anesthetic agents may affect the cardiovascular system with different mechanisms and cause severe arrhythmias. It will be beneficial to discuss the normal cardiac cycle to better understand arrhythmias. As is known, normal cardiac conduction begins with cardiac impulses coming from the sinoatrial (SA) node. From here the impulse first passes the atrioventricular (AV) node, then reaches the His bundle and Purkinje fibers transforming into conduction causing ventricular contraction (Beton and Tandoğan, 2011; Kwon and Kim, 2017). The normal heart rate of adults is $60-100$ beats/min. Arrhythmias occur depending on disorders in the formation of this impulse and/or during conduction (Zoghi and Duygu, 2006).

\section{Perioperative arrhythmias}

To identify the arrhythmias, anesthesiologists need to know how to interpret basic ECG procedure (Fig $1)$.

\begin{tabular}{|ll|}
\hline- & Analysis P wave \\
- & Analysis QRS complex \\
- & Determine PR interval \\
- & Determine ventricular rhtyhm or regularity \\
- & Analysis T wave \\
- & Determine heart rate \\
\hline
\end{tabular}

Figure 1. Basic procedure of rhythm analysis

Sinus bradycardia: This is defined as a regular rhythm with heart rate below 60 beats/min (Fig 2). It may be observed as normal in healthy elderly patients and sportive young people. Additionally, it is observed in situations with the use of anti-

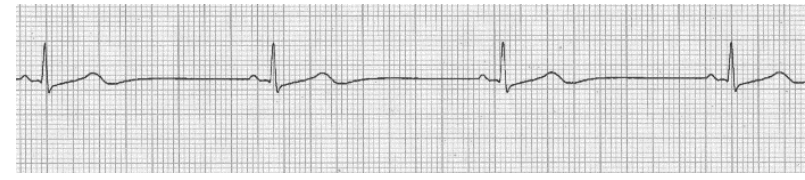

Figure 2. Sinus bradycardia

arrhythmics (beta blockers, etc.), the effect of anesthetic medications (opioids, inhalation agents, succinylcholine), increased reflex vagal stimuli and increased intracranial pressure. Symptomatic bradycardia should be treated with atropine; if no response occurs, giving adrenalin or inserting a pacemaker should be considered. As the American Society of Anesthesiologists (ASA) classification risk increases, it is known the probability of bradycardia increases (Erdemli and Çekmen, 2010; Timuralp, 2010; Yapıcı and Azizoğlu, 2015).

Sinus tachycardia: This is defined as a regular rhythm with heart rate generally above 100 beats/min (Fig 3). It is most commonly observed in situations with hypovolemia, increased body temperature, pain sensation, hypercarbia, anemia and hyperthyroidism. Tachycardia accompanying anesthesia may be related to dangerous situations like malignant hyperthermia and myocardial ischemia. This arrhythmia generally resolves with intervention to the underlying cause, and symptomatic tachycardia disrupting hemodynamics should be rapidly treated (Yapıcı and Azizoğlu, 2015; Kwon and Kim, 2017). Treatment choices include non-dihydropyridine calcium channel blockers (diltiazem, verapamil), beta blockers and digitalis.

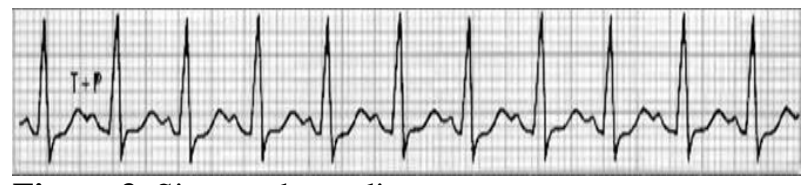

Figure 3. Sinus tachycardia

Sinus arrhythmia: This is an arrhythmia related generally to respiration with no significant clinical and hemodynamic importance. There is a pattern of increasing with inspirium and reducing with expirium. It occurs due to the SA node being affected by vagal stimuli (Timuralp, 2010; Yapıc1 and Azizoglu, 2015). It is generally observed in children and young people. It does not require treatment. 
Sick sinus syndrome: This is defined as the combination of bradycardia and SA block. It should be recalled when elderly patients under anesthesia develop sudden bradycardia. Pacemaker treatment has the most importance for treatment (Erdemli and Cekmen, 2010).
AV Blocks: AV node diseases occur with increased vagal tonus, coronary artery disease, infections, endocrine causes, neuromuscular diseases and some medications (Fig 4).

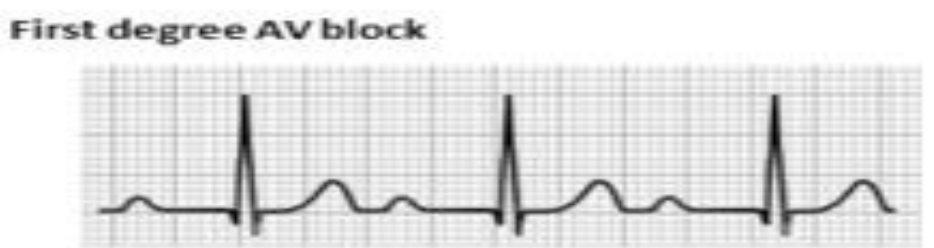

Second degree AV block (Mobitz I or Wenckebach)

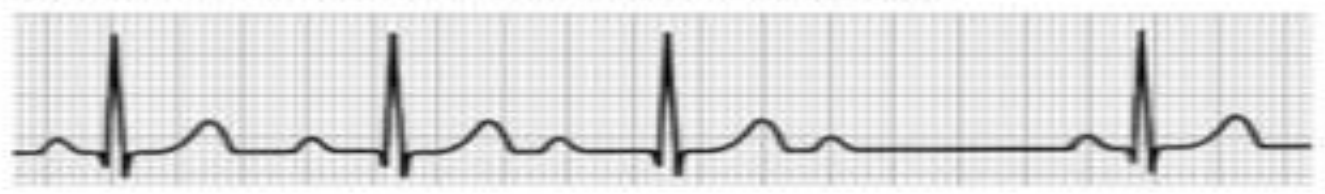

Second degree AV block (Mobitz II)

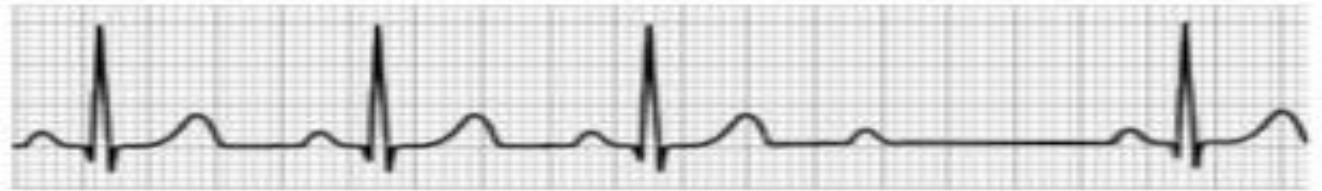

Second degree AV block (2:1 block)

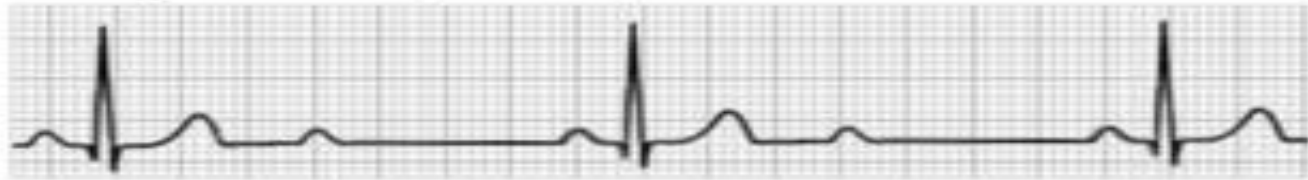

Third degree AV block with junctional escape

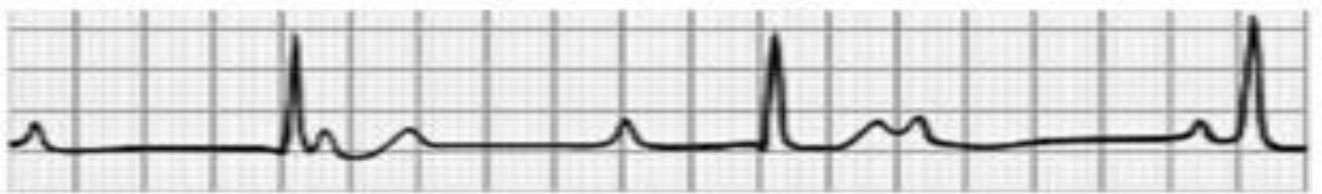

Figure 4. AV Blocks

In first degree AV block, a lengthened PR interval is present. It may be observed in normal individuals and generally does not require treatment.

Second degree AV block may be separated in two as Mobitz type I (Wenckebach) and Mobitz Type II. In Mobitz type I the PR interval continuously increases. In some Mobitz type II cases no P wave passes the ventricle and $2: 1$ or $3: 1$ block forms occur. If it is symptomatic, iv atropine or a pacemaker may be required.

In third degree AV block no atrial impulse passes the Purkinje system. The atrium and the ventricles spasm independently and the heart fails to produce sufficient cardiac output. There are indications for a pacemaker in these cases (Erdemli and Cekmen, 2010; Timuralp, 2010).

Sinoatrial blocks: These occur when stimuli from the sinus node do not stimulate the atrium. For treatment atropine may be administered. Hemodynamically unstable cases should be assessed for a pacemaker. 
Intraventricular blocks: These occur due to blockage or delayed conduction in the right or left branch of the His bundle. Widened QRS is present.

a) Right bundle branch block: A second $R$ wave ( $R^{\prime}$ ) observed on precordial derivations (V1-3) and deep S wave observed on DI, aVL, V5 and V6 derivations. Just as it may be observed in healthy individuals, it may be observed with ischemic heart disease, rheumatic heart diseases and hypertension (Akyel and Tavil, 2010).

b) Left bundle branch block: QRS duration is longer than $0.12 \mathrm{~s}$, notching of the QRS complex on V5, V6, DI and aVL, monophasic broad R waves on DI, DII, V5 and V6 derivations and deep S wave pattern on V1-3. Left bundle branch block accompanies cardiac diseases like ischemic heart diseases, aorta stenosis, hypertension, cardiomyopathies and rheumatic heart diseases. Treatment of the cause is priority (Akyel and Tavil, 2010).

Atrial extrasystole: This is observed as early and abnormal depolarization of the atrium and following this a normal QRS wave. It is sourced in an ectopic focus in the atrium apart from the SA node. Generally, it does not require treatment; however, it may be a harbinger of other atrial arrhythmias like atrial fibrillation (Yapic1 and Azizoglu, 2015; O’Neal et al., 2017).

Junctional rhythm (Nodal Rhythm): This occurs when the pacemaker activity of the AV node exceeds the sinus node with the stimuli returning within the atrium. It may be divided into 3 groups as slow, moderate and rapid. The rate is generally between $50-180$ beats/min. It may cause a fall in blood pressure and cardiac output. If it is symptomatic atropine and ephedrine may be administered (Erdemli and Cekmen, 2010; Timuralp, 2010).

Supraventricular tachycardia: This may be observed with heart diseases, systemic diseases, thryotoxicosis, digital toxicity, pulmonary emboli and pregnancy. It may cause serious hemodynamic changes.

Paroxysmal supraventricular tachycardia (PSV): This is a regular and fast arrhythmia with QRS waves close to normal shape. It begins suddenly with rate generally from 150-250 beats/min. The duration of the attacks is variable, and may cause no problems in healthy individuals. However, in situations with cardiac ischemia it may cause severe hemodynamic disruption and respiratory distress. Carotid massage and vagal stimulation are effective for stopping attacks; however, in situations without resolution medications like adenosine, verapamil, edrophonium and digitalis or cardioversion may be administered.

Atrial tachycardia: This is an arrhythmia type sourced in the atrium and frequently indicates some primary disease (Fig 5). The most important cause of this arrhythmia is automaticity increasing. The heart rate is variable. For treatment, beta blockers and adenosine may be used (Erdemli and Çekmen, 2010; Yapıcı and Azizoğlu, 2015).

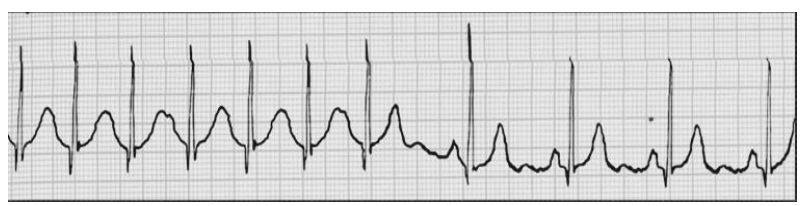

Figure 5. Atrial tachycardia

Atrial flutter: This may be defined as rapid atrial tachycardia. In the majority of cases, "reentry" forms the basic mechanism. Heart rate is 250-350 beats/min and $\mathrm{f}$ waves with saw-tooth appearance are typical. The ventricular rate is regular and the ratio is commonly $2: 1,3: 1$ and $4: 1$. It may be observed together with hyperthyroidism, ischemic heart diseases or rheumatic heart diseases (Yapic1 and Azizoglu, 2015). Medication treatment with verapamil, digitalis and beta blockers is rarely effective. If cardioversion is administered, treatment is effective for $90 \%$ of cases and generally it is used as the first treatment choice (Erdemli and Cekmen, 2010).

Atrial fibrillation (AF): This is an arrhythmia type sourced in more than one focus in the atrium. Insufficient contraction causes a reduction in ventricular filling. The ventricular rate is lower than the atria and irregular. On EKG there is no $\mathrm{P}$ wave and pulse deficit is present. QRS waves are generally narrow and irregular (Fig 6). While atrial rate is $350-500$ beats $/ \mathrm{min}$, ventricular rate is in the interval $60-170$ beats $/ \mathrm{min}$. AF is observed in nearly $10 \%$ of geriatric patients in the general population and is the most common arrhythmia type in the elderly. It accompanies situations like mitral valve disease, myocardial infarctus, heart failure, HT, diabetes, obesity, hyperthyroidism and COPD. It 


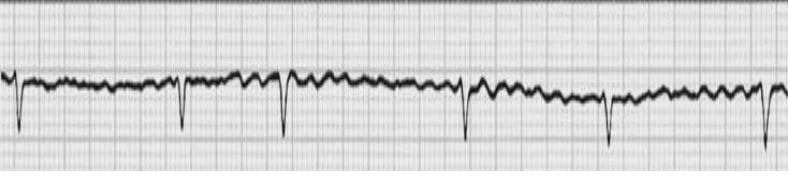

Figure 6. AF

causes cerebrovascular and systemic embolism due to atrial thrombus. The main aim of treatment is to bring the ventricular response under control and specially to begin anticoagulant prophylaxis due to the risk of thromboembolic stroke. For medical treatment, verapamil, beta blockers, amiodarone and digoxin are appropriate. For newly begun AF, the most appropriate treatment choice is medical or electrical cardioversion accompanied by anticoagulants (Erdemli and Cekmen, 2010; Melek, 2010; Yap1c1 and Azizoglu, 2015).

Ventricular extrasystole (VES): This may be due to any focus in the ventricle. It is commonly linked to myocardial ischemia and indicates poor prognosis for ischemic heart diseases. In ECG trnascription there are broad abnormal QRS waves and following this $\mathrm{T}$ waves in the inverse direction are observed. There is no $\mathrm{P}$ wave in ECG before QRS waves (Fig 7). The first choice for medical treatment is lidocaine. Quinidine, bretylium, propranolol and verapamil are other appropriate choices in treatment (Erdemli and Cekmen, 2010; Hasdemir, 2010, Yapıcı and Azizoglu, 2015).

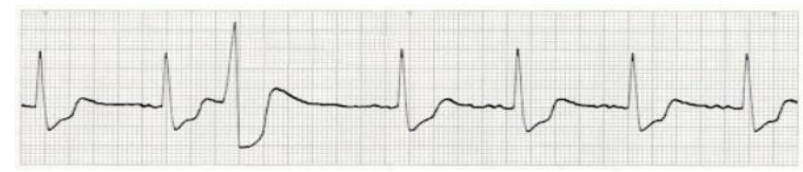

Figure 7: VES

Ventricular tachycardia: This appears as rapid and regular QRS complexes on ECG; however, the $\mathrm{P} / \mathrm{QRS}$ ratio is not fixed. There is a tachycardia source in the ventricles with rate in the interval 120220 beats/min. Carotid massage commonly provides no response. Ventricular tachycardia is a very serious arrhythmia. The majority of the time it may occur as a complication of hypoxia, hemorrhage, some medications (like adrenalin and atropine) and serious heart diseases. However, the most common cause is ischemic heart disease. Attacks may sometimes last hours. In situations with hemodynamic instability and collapse, the patient should immediately have the inspired oxygen concentration increased, iv lidocaine should be administered and emergency synchronized cardioversion applied. Other medical choices may be amiodarone and propafenone. Additionally, it is necessary to terminate the surgical operation and anesthesia (Erdemli and Cekmen, 2010; Hasdemir, 2010; Yap1c1 and Azizoglu, 2015).

Ventricular Fibrillation (VF): Rapid and irregular electrical activity causes a situation where the ventricles do not contract synchronously causing sudden loss of cardiac output (Fig 8). It is a malignant arrhythmia occurring with myocardial ischemia, hypoxia, hypothermia, electrolyte imbalance and medication effects. The patient will only survive with cardiopulmonary resuscitation and defibrillation. These should be applied together with supportive care (Erdemli and Çekmen, 2010; Hasdemir, 2010; Yapıcı and Azizoglu, 2015).

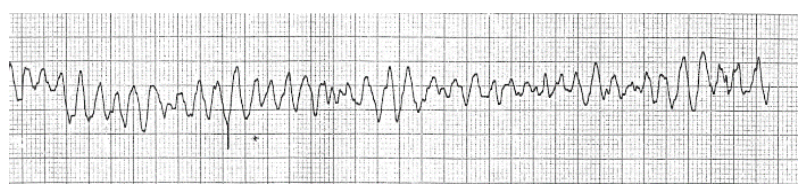

Figure 8: VF

Wolf Parkinson White Syndrome; This may be coincidentally identified on ECG during preoperative examination. The $\mathrm{P}$ waves have normal shape and the PR interval is short. There is a wave called a "delta wave" at the beginning of the $\mathrm{R}$ wave lengthening the QRS complex. Commonly it is observed together with ST depression or T wave inversion. When accompanied by atrial fibrillation there is a risk of sudden death. For treatment, radiofrequency catheter ablation should be used. In this patient group, antiarrhythmic medications like beta blockers suppressing the AV node and nondihydropyridine group $\mathrm{Ca}$ channel blockers are contraindicated (Erdemli and Cekmen, 2010; Yapıcı and Azizoglu, 2015).

Cardiac arrest/asystole: This is an arrhythmia type with no ventricular activity. The ECG is in the form of a fully straight line. It requires immediate intervention. The only treatment is cardiopulmonary resuscitation (Erdemli and Cekmen, 2010).

Causes of perioperative arrhythmias: Common causes of perioperative arrhythmias are shown in Table 1 and primary treatment methods are shown in Table 2. The perioperative arrhythmia incidence for patients with predisposing pathologies is higher compared to other patients (Flegal et al., 
2009; Erdemli and Cekmen, 2010).

Table 1. Common causes of perioperative arrhythmias

- Anesthetic agents (volatile or intravenous agents, neuromuscular blockers, opioids)

- Local anesthetics

- Hypotermia

- Acid - base or electrolyte imbalance

- Hypoxia - hypercarbia

- Anesthesia depth

- Surgery types (ocular - cranial interventions, peritoneal traction...)

- Comorbidities (cardiac, endocrin, others)

- Laryngoscopy, intubation, other irritating factors

- Alternative drugs (adrenaline...)

- Artifacts

Table 2. Primary treatment approach of common perioperative arrhythmias

\begin{tabular}{|l|l|}
\hline Sinus bradycardia & $\begin{array}{l}\text { Atropine, adrenalin or } \\
\text { pacemaker }\end{array}$ \\
\hline Sinus tachycardia & $\begin{array}{l}\text { Calcium channel blockers } \\
\text { (diltiazem, verapamil), beta } \\
\text { blockers and digitalis }\end{array}$ \\
\hline Sick sinus syndrome & Pacemaker \\
\hline $\begin{array}{l}\text { Paroxysmal } \\
\text { supraventricular } \\
\text { tachycardia }\end{array}$ & $\begin{array}{l}\text { Carotid massage, adenosine, } \\
\text { verapamil, edrophonium, } \\
\text { digitalis, cardioversion }\end{array}$ \\
\hline Atrial tachycardia & Beta blockers and adenosine \\
\hline Atrial fibrillation & $\begin{array}{l}\text { Anticoagulant prophylaxis, } \\
\text { verapamil, beta blockers, } \\
\text { amiodarone, cardioversion }\end{array}$ \\
\hline Ventricular extrasystole & $\begin{array}{l}\text { Lidocaine, quinidine, } \\
\text { bretylium, propranolol and } \\
\text { verapamil }\end{array}$ \\
\hline Ventricular fibrillation & $\begin{array}{l}\text { Cardiopulmonary } \\
\text { resuscitation and } \\
\text { defibrillation }\end{array}$ \\
\hline
\end{tabular}

Disruption of acid-base or electrolyte balance affects the conduction system, especially causing arrhythmias with the re-entry mechanism. The most common causes of anesthesia-related arrhythmias are disruption of oxygenization and carbon dioxide excretion. In the early period, arrhythmia occurs with stimulating effects from the aorta and carotid receptors, while in the later period inhibitory mechanisms are effective. In disrupted oxygenation, slightly lower oxygen saturation levels compared to normal have a stimulating effect, while lower oxygen values cause depressant effects. Increased carbon dioxide level increases the oxygen requirements of the myocardium and causes acidosis, bradycardia and a fall in cardiac output (Trappe et al., 2003; Erdemli and Cekmen, 2010). Another important factor causing arrhythmia is whether anesthesia is slightly or deeply. While blocks and asystole may be caused by deeply anesthesia, slightly anesthesia is the most common cause of tachycardia (Balser, 2002). General anesthesia, laryngoscopy and intubation procedures linked to it cause sympathetic activation and trigger tachycardia and disrhythmia especially. Ocular interventions, cranial surgeries and the other surgeries where the peritoneum is pulled cause arrhythmias and bradycardia due to different mechanisms (Balser, 2002; Trappe et al., 2003; Erdemli and Cekmen, 2010). As is known, one of the most important effects of anesthetic agents on the cardivascular system is arrhythmia. Inhalation agents change the autonomous nervous system or conduction speed in cardiac cycle causing arrhythmia. Agents with halogene hydrocarbon structure cause arrhythmia formation with the reentry mechanism. Halotan affects the myocardium sensitivity to catecholamines showing arrhythmogenic effect. Nitrous oxide is an agent with cardiac depressant effects. Intravenous anesthetics blocks the uptake of noradrenalin from adrenergic nerve endings like ketamine causing sympathetic stimulation and facilitate the occurrence of arrhythmia (Balser, 2002; Erdemli and Cekmen, 2010). Thiopental causes significant tachycardia and arrhythmia during induction. Increases occur in heart rate and oxygen consumption of the myocardium. During apnea in thiopental induction, administering high concentrations of oxygen to the patient is reported to be beneficial to prevent arrhythmia (Erdemli and Cekmen, 2010). Propofol clearly reduces blood pressure, causing variable effects on heart rate. With severe aorta stenosis and hypertension, it should not be forgotten that propofol reduces coronary perfusion causing myocardial ischemia. Etomidate is the agent with fewest cardiac side effects among iv induction agents and is the most appropriate induction agent for patients with additional cardiac pathologies. Among benzodiazepines, diazepam causes reflex tachycardia while midazolam shows a negative inotropic effect. Opioids depress the SA node with direct effect, while they indirectly increase acetylcholine release and cause bradycardia. Fentanyl causes bradycardia linked to vagal stimulation, while morphine has a positive chronotropic effect with dose-linked endogenous 
catecholamine increase. Meperidine causes significant histamine release leading to tachycardia. The neuromuscular blocker of succinylcholine is well known to have arrhythmogenic and bradycardiac effects. Especially with the potassium increase it causes, the incidence of arrhythmias increases. Repeated succinylcholine doses trigger arrhythmia. Vecuronium has bradycardiac effect, while atracurium causes tachycardia via histamine release. Mivacurium and rocuronium have fewer cardiac side effects encountered (Hunter 2002). The arrhythmic effect of local anesthetics forms due to binding in voltage-gated sodium channels in the nerve cell membrane. Local anesthetic toxicity is a serious event progressing to cardiovascular collapse. All anesthetic workers should be informed about this topic and close monitoring of the patient is important. It is reported that administering lipid solution before cardiovascular collapse occurs increases survival (Suzer et al., 2011).

Perioperative approach: First it should be stated that it is necessary to complete the preoperative evaluation of patients effectively and linked to this, to determine the most appropriate anesthesia management. It is possible to encounter predisposing factors or cardiac pathologies in every age group; however, all these situations do not always cause ECG changes in the preoperative period and unfortunately the majority of the time arrhythmias occur unexpectedly (Mandim et al., 2004). Preoperative assessment should determine firstly the patient's history, medications used, biochemical values and predisposing factors for arrhythmia (Duncan and Wijeysundera, 2016). Patients in the risk group should have detailed assessment and then consultation with cardiology and it is important to prepare the patient in the best conditions for surgery and share risks based on this recommendation. Situations like acid-base balance disorder, electrolyte imbalances, cardiac pathologies, hypoxia and variations in body temperature that prepare the way for arrhythmias should be resolved at optimum levels to ensure the patient is stable (Rafiq et al., 2017). With regional anesthesia, patients should be more closely monitored for hypotension, bradycardia and sudden cardiac arrest, with patients monitored for rhythm, respiration and hemodynamics during every type of anesthesia administration. Carefully rhythm monitoring in perioperative period is undoubtedly the most important method for diagnosis. One topic that should be mentioned related to rhythm analysis is artifacts. These images observed on ECG that cannot be interpreted should be identified by the anesthesiologist and confirmed as artifacts. If confirmation is not possible, monitoring should be performed with a different device and confirmation of any incompatibility between simultaneous arrhythmia imaging and the clinical and hemodynamic findings of the patient made.

\section{Conclusion}

It is known that that possibility of encountering arrhythmia at every stage of routine anesthesia practice is high. The patient should be carefully assessed for the possibility of every type of arrhythmia and ECG analysis should be accurately completed. For this topic, anesthesiology specialization students should be given sufficient rhythm analysis training. It is clear that simulation training involving arrhythmia scenarios including cardiopulmonary resuscitation will be beneficial. All operating rooms should have monitors, defibrillators and all material necessary to deal with arrhythmias present and ready for use and these should be checked daily. Operating rooms and delivery rooms should definitely have $20 \%$ lipid solution for use in local anesthetic toxicity ready. Additionally, an action plan should be created for emergency situations with personnel informed about their responsibilities for procedures in the plan. Early diagnosis and early intervention are life saving for arrhythmias.

Peer-review: Externally peer-reviewed.

Author Contributions: Concept- A.A., N.T., O.B., Design- A.A., Supervision- A.A., N.T., Literature Review- A.A., N.T., Writing- A.A., N.T., O.B., Critical Review- A.A., N.T., O.B.,

Conflict of Interest: No conflict of interest was declared by the author.

Financial Disclosure: The authors declared that this study has /hasn't received no financial support.

\section{References}

Akyel A, Tavil Y. Arrhythmias in Acute Myocardial Infarction; Reasons and Treatment Approaches. Bülent Görenek. Arrhythmias; Reasons, Current Diagnosis and Treatment Methods (Aritmiler; Nedenleri, Güncel Tanı ve Tedavi Yöntemleri). İstanbul: Nobel Medical Publishers; 2010. p.445-49. 
Balser JR. Perioperative arrhythmias: incidence, risk assessment, evaluation, and management. Card Electrophysiol Rev. 2002 Feb;6(1-2):96-9.

Beton $\mathrm{O}$, Tandoğan İ. Conduction system of the heart. Türkiye Klinikleri J Cardiol-Special Topics 2011;4(6):1-8.

Duncan D, Wijeysundera DN. Preoperative cardiac evaluation and management of the patient undergoing major vascular surgery. Int Anesthesiol Clin 2016;54(2):1-32.

Erdemli Ö, Çekmen N. Arrhythmias and anesthesia. Türkiye Klinikleri J Anest Reanim 2010;3(1):43-53.

Flegal MC, Fox LK, Kuhlman SM. Principles of anesthesia monitoring and electrocardiogram. J Invest Surg. 2009 Jul-Aug;22(4):316-7.

Hasdemir C. Ventricular Arrhythmias: Definitions, Reasons and Formation Mechanisms. Bülent Görenek. Arrhythmias; Reasons, Current Diagnosis and Treatment Methods (Aritmiler; Nedenleri, Güncel Tanı ve Tedavi Yöntemleri). İstanbul: Nobel Medical Publishers; 2010. p.297-306.

Hunter JM. Neuromuscular blocking and reversal agents. In: Hutton P, Cooper GM, James F, Butterworth JF (eds). Fundamental principles and practice of anaesthesia. 1 st ed. London: Martin Dunitz Ltd, The livery House 2002:63344.

Kwon $\mathrm{CH}$, Kim $\mathrm{SH}$. Intraoperative management of critical arrhythmia. Korean J Anesthesiol. 2017 Apr;70(2):120-126.

Mandim BL, Achá RE, Fonseca NM, Zumpano F. Cardiac arrhythmias and ST changes in the perioperative period of elderly patients submitted to transurethral prostatectomy under spinal anesthesia: comparative study. Rev Bras Anestesiol. 2004 Apr;54(2):190-203.

Melek M. Atrial Fibrillation; Clinical Significance, Reasons. Bülent Görenek. Arrhythmias; Reasons, Current Diagnosis and Treatment Methods (Aritmiler; Nedenleri, Güncel Tanı ve Tedavi Yöntemleri). İstanbul: Nobel Medical Publishers; 2010. p.227-247.

O'Neal WT, Kamel H, Judd SE, Safford MM, Vaccarino V, Howard VJ, Howard G, Soliman EZ. Usefulness of Atrial Premature Complexes on Routine Electrocardiogram to Determine the Risk of Atrial Fibrillation (from the REGARDS Study). Am J Cardiol. 2017 Sep 1;120(5):782-785.
Polanczyk CA, Goldman L, Marcantonio ER, Orav EJ, Lee TH. Supraventricular arrhythmia in patients having noncardiac surgery: clinical correlates and effect on length of stay. Ann Intern Med. 1998 Aug 15;129(4):279-85.

Rafiq A, Sklyar E, Bella JN. Cardiac Evaluation and Monitoring of Patients Undergoing Noncardiac Surgery. Health Serv Insights 2017; doi: 10.1177/1178632916686074

Süzer MA, Özhan MÖ, Eşkin MB, Atik B, Çaparlar C. Local Anesthetic Toxicity Managed Successfully with Lipid Infusion (Case Report) Türk Anest Rean Der Dergisi 2011; 39(3):15963.

Thompson A, Balser J.R. Perioperative cardiac arrhythmias. Br J Anaesth 2004; 93(1):86-94.

Timuralp B. Physical Examination in Diagnosis of Arrhythmias. Bülent Görenek. Arrhythmias; Reasons, Current Diagnosis and Treatment Methods (Aritmiler; Nedenleri, Güncel Tanı ve Tedavi Yöntemleri). İstanbul: Nobel Medical Publishers; 2010. p. 9-17.

Trappe HJ, Brandts B, Weismueller P. Arrhythmias in the intensive care patient. Curr Opin Crit Care. 2003 Oct;9(5):345-55.

Tyler CL. Intraoperative cardiac emergencies. Crit Care Nurs Clin North Am. 2015 Mar;27(1):1731.

Yapıc1 D, Azizoğlu M. Arrhythmias and Anesthesia. Section 19. A. Dönmez, Z. Özer, A. Kararmaz. Anesthesia and Heart (Anestezi ve Kalp). Türkiye: 2015: p. 379-402. Available from: URL: http://www.tard.org.tr/akademi

Zoghi M, Duygu H. Electrophysiology of rhythm disorders and classification of arrhythmias. Türkiye Klinikleri J Int Med Sci 2006;2(33):605. 